\title{
Остаться нельзя уйти: к вопросу о развитии угольной генерации в России ${ }^{1}$
}

\author{
В.Н. ЧУРАШЕВ, кандидат экономических наук, доцент, Институт экономики \\ и организации промышленного производства CO РАН. E-mail: tch@ieie.nsc.ru \\ В.М. МАРКОВА, кандидат экономических наук, Институт экономики \\ и организации промышленного производства СО РАН, Новосибирский \\ государственный университет, Новосибирск. E-mail: mvm@ieie.nsc.ru \\ ORCID: 0000-0003-1537-3240
}

Аннотация. Анализируются возможности мировой и российской угольной генерации с точки зрения сохранения ее позиций в структуре энергетики, ее противостояние современным экономическим, экологическим и технологическим вызовам, среди которых отмечены следующие: борьба с изменением климата и переход к низкоуглеродной энергетике, ведущие к ужесточению экологических требований к выбросам электростанций; рост вводов генерации на основе возобновляемых источников энергии в результате реализации государственных программ их поддержки и кратного снижения стоимости; усиление межтопливной конкуренции с газом (при снижении его цены). Показано, что технологическое развитие является определяющим для сохранения доли угольных станций как в мире, так и в России. Рассматриваются различные направления расширения присутствия угольной генерации: модернизация теплоэлектростанций, строительство новых станций с учетом чистых угольных технологий (ССТ и HELE), замещение котельных мини-ТЭЦ, строительство энерготехнологических комплексов. Показано, что в Сибири ввод мощностей других типов генерации маловероятен в качестве альтернативы угольной энергетике. В связи с отсутствием тенденций к росту спроса на электроэнергию в среднесрочной перспективе дальнейшее строительство крупных угольных станций вряд ли возможно без развития энергетических связей с Юго-Восточной Азией.

Ключевые слова: угольная генерация; Сибирь; экологическая и экономическая эффективность; энергетические мощности; чистые угольные технологии

Вопрос о том, сможет ли угольная генерация, со всеми ее достоинствами и недостатками, противостоять вызовам развития мировой энергетики, в последние годы часто поднимается как в мировых прогнозах, так и в региональных. Очевидно, на него нет однозначного ответа, так как многое зависит от того, какой именно источник в конкретном регионе покажет наибольшую экономическую и экологическую эффективность. За последние 15 лет оценки в перспективах развития угольной генерации менялись

${ }^{1}$ Статья подготовлена по плану НИР ИЭОПП СО РАН в рамках проекта ХI.172.1.1 № AAAA-A17-117022250132-2 
весьма значительно. От периодически возникающих «оптимистических» версий второй, третьей угольной волны до перспектив практически полного сокращения угольной энергетики.

Несмотря на то, что в последние десятилетия сланцевая революция, возобновляемые источники энергии, атомная генерация заметно изменили энергетический ландшафт в мире, угольная энергетика по-прежнему остается одним из основных источников дешевой электроэнергии для стимулирования экономического роста. Главные преимущества угля как источника электроэнергии широко известны:

- распространенность и доступность в разных регионах мира;

- большие запасы;

- относительно низкая стоимость угля как энергетического топлива (особенно в регионах его добычи);

- возможность создания запасов на электростанциях, гарантирующих долгосрочную надежную работу даже в случае перебоев с поставками топлива.

Эти особенности позволяют угольной генерации не просто сохранять важную роль в энергетическом секторе, но и расширять свое влияние во многих странах мира. С 2000 г. по 2019 г. количество стран, использующих угольные станции, выросло с 65 до 77. Еще 13 стран планируют вступить в клуб угольной энергетики [World.., 2018].

В последнее десятилетие мировую динамику угольной генерации определяют разнонаправленные тенденции:

- развитие угольной энергетики в развивающихся экономиках (Китай, Индия и Турция, другие страны ЮВА);

- сокращение ее объемов в развитых экономиках Европы и США при снижении спроса на энергию в целом.

За 2000-2018 гг. доля угольных ТЭС в мировой структуре мощности электроэнергетики значительно сократилась (с 47,6\% до 30,9\%), в то время как их вклад в объем выработки практически не изменился (38-41\%, и это самая большая доля в сравнении с другими типами генерации) (табл. 1). Такое различие в динамике мощности и выработки электроэнергии обусловлено тем, что значительные вводы мощностей ВИЭ не обеспечивают столь же значимый прирост производства электроэнергии вследствие низкого значения коэффициента использования мощности (часто менее 15\%). 
Таблица 1. Динамика мощностей и выработки электроэнергии на угле в мире в 1990-2018 гг.

\begin{tabular}{|l|c|c|c|c|c|}
\hline \multicolumn{1}{|c|}{ Показатель } & $\mathbf{1 9 9 0}$ & $\mathbf{2 0 0 0}$ & $\mathbf{2 0 1 0}$ & $\mathbf{2 0 1 8}$ & $\mathbf{2 0 1 8 / 2 0 0 0}$ \\
\hline Мощность всего, ГВ·т & 2830 & 3437 & 5510 & 6681 & 1.94 \\
\hline Выработка электроэнергии всего, ТВт·ч & 11955 & 15548 & 21574 & 26615 & 1.71 \\
\hline Мощность угольных станций, ГВт & 785 & 1063 & 1658 & 2027 & 1.91 \\
\hline $\begin{array}{l}\text { Выработка электроэнергии на угольных } \\
\text { станциях, ТВт·ч }\end{array}$ & 4457 & 5985 & 8658 & 10101 & 1.69 \\
\hline
\end{tabular}

Источник: World Energy Outlook-2018; BP Energy Outlook 2018, Статистический ежегодник мировой энергетики. URL: https://yearbook.enerdata.ru

В течение указанного периода мировые мощности угольной генерации выросли с 1063 до 2027 ГВт. Особенно бурное развитие наблюдалось в период с 2010 г. по 2015 г., когда ежегодный ввод мощностей достиг своего максимума - 473 ГВт. Начиная с 2015 г., когда было введено 110 ГВт, этот показатель постепенно снижается, и в 2018 г. было введено всего 34 ГВт мощностей, работающих на угле [World.., 2018; ВР Energy.., 2018].

По вводам новых мощностей угольных тепловых электростанций безусловными лидерами являются Китай и Индия, которые обеспечивали от 50 до 90\% глобальных вводов ежегодно в течение 2006-2018 гг. (суммарно более 870 ГВт). Однако после 2015 г. наблюдается замедление инвестиций в угольные ТЭС, что в перспективе, как указывают многие эксперты, приведет к достижению пика глобальной мощности угольной генерации уже в 2022 г. [World.., 2018; BP Energy.., 2018; Угольная генерация.., 2019; International.., 2017].

В 2018 г. угольные станции во всем мире выработали 38\% электроэнергии (табл. 2), что в полтора раза больше, чем газовые, и почти совпадает с объемами производства всех АЭС, ГЭС и ВИЭ вместе взятых. При этом мировой рынок угольной генерации характеризуется высокой степенью концентрации, тринадцать стран обеспечивают в последние годы около 90\% выработки электроэнергии на угле, а суммарная доля Китая, США и Индии составляет почти 70\% [BP Energy.., 2018; Угольная генерация.., 2019; International.., 2017]. В четырех странах (ЮАР, Польша, Индия и Китай) более половины произведенной электроэнергии в 2018 г. было получено из угля. 
Таблица 2. Доля угольной генерации в структуре выработки энергии по странам в 1990-2018 гг., \%

\begin{tabular}{|l|c|c|c|c|c|c|}
\hline \multirow{2}{*}{ Страна } & \multicolumn{3}{|c|}{ Доля угля в общем объеме выра- } & \multicolumn{2}{c|}{$\begin{array}{c}\text { Доля страны в общем объеме } \\
\text { мировой угольной генерации }\end{array}$} \\
\cline { 2 - 7 } & $\mathbf{1 9 9 0}$ & $\mathbf{2 0 0 0}$ & $\mathbf{2 0 1 0}$ & $\mathbf{2 0 1 8}$ & $\mathbf{2 0 0 0}$ & $\mathbf{2 0 1 8}$ \\
\hline Мир в целом & 37 & 38,6 & 40,1 & 38,0 & 100,0 & 100,0 \\
\hline США & 53 & 52,5 & 45,5 & 27,9 & 35,6 & 12,3 \\
\hline Китай & 71 & 78,2 & 77,0 & 66,5 & 17,7 & 46,9 \\
\hline Индия & 67 & 68,3 & 68,6 & 71,6 & 6,5 & 11,6 \\
\hline ЕС-28 & 40 & 37,1 & 24,5 & 19,2 & 15,8 & 6,2 \\
\hline Германия & 57 & 50,5 & 41,5 & 35,3 & 4,9 & 2,3 \\
\hline Великобритания & 65 & 31,8 & 28,2 & 5,0 & 2,0 & 0,2 \\
\hline Польша & 96 & 95,0 & 87,8 & 79,2 & 2,3 & 1,3 \\
\hline Италия & 16 & 11,0 & 14,7 & 12,6 & 0,5 & 0,4 \\
\hline Турция & 35 & 30,6 & 26,0 & 36,9 & 0,6 & 1,1 \\
\hline Канада & 17 & 19,0 & 13,8 & 9,1 & 1,9 & 0,6 \\
\hline Индонезия & 30 & 36,4 & 40,3 & 58,5 & 0,6 & 1,5 \\
\hline Южная Корея & 26 & 37,7 & 44,3 & 44,1 & 1,8 & 2,6 \\
\hline Япония & 14 & 20,4 & 27,1 & 33,0 & 3,7 & 3,4 \\
\hline ЮАР & 93 & 91,7 & 92,6 & 87,9 & 3,2 & 2,2 \\
\hline Австралия & 79 & 83,2 & 70,1 & 59,9 & 3,0 & 1,6 \\
\hline Россия & 14,0 & 20,0 & 18,0 & 16,0 & 2,9 & 1,8 \\
\hline
\end{tabular}

Источник: World Energy Outlook-2018; BP Energy Outlook 2018.

В ряде стран с развитой угольной энергетикой на протяжении всего рассматриваемого периода сохранялись относительно стабильные объемы выработки, в их числе Польша, Россия, Австралия, ЮАР, Южная Корея. В Японии произошел резкий скачок доли угольной генерации в энергобалансе страны из-за аварии на АЭС «Фукусима» в 2011 г. Пик мировой выработки электроэнергии из угля был достигнут в 2014 г., на данный момент мы наблюдаем очередную волну снижения загрузки действующих ТЭС и их закрытия.

\section{Вызовы для угольной генерации}

В последние годы угольная генерация столкнулась с серьезными вызовами - экологическими, технологическими, экономическими, политическими и социальными.

Борьба с изменением климата и переход к низкоуглеродной энергетике, приведшие к ужесточению экологических требований к ТЭЦ, рост генерации на основе возобновляемых источников 
энергии (ВИЭ) в результате масштабной господдержки и кратного снижения стоимости этих технологий, усиление межтопливной конкуренции с газом (при снижении его цены) - вот далеко не полный перечень вызовов, с которыми сталкивается угольная генерации как в мире, так и в России.

Кроме того, масштабное внедрение ВИЭ-генерации обусловливает развитие энергосетевой структуры, что в свою очередь предъявляет к станциям на традиционном топливе дополнительные требования к повышению гибкости для балансирования стохастической выработки ВИЭ. И сегодня именно угольные станции чаще всего выступают как резервные, обеспечивая диверсификацию топливного баланса и гарантируя энергообеспечение в случае форс-мажорных ситуаций [Веселов и др., 2017]. Отдельным фактором выступает замедление роста или снижение энергопотребления в развитых странах, что вынуждает их правительства принимать решения по оптимизации генерирующих мощностей.

Угольная генерация, выбросы которой изобилуют золой, диоксидом серы, оксидами азота, тяжелыми металлами и т.д., предсказуемо становится первой жертвой ужесточения экологических требований, хотя современные технологии значительно повысили ее экологическую безопасность. К тому же существуют (и сохранятся в будущем) как региональные особенности, так и различные подходы к развитию (ограничению) угольной энергетики.

Из всех факторов, влияющих на замещение угольных мощностей, возлагать главную вину на «победоносное шествие» ВИЭ пока особых оснований нет. В энергетическом секторе ощущение перемен часто опережает реальность. В большинстве случаев всё решают рынок и развитие технологий [Попов, 2019; Макаров и др., 2017]. Там, где выгоднее и доступнее становится природный газ, именно он определяет темпы вывода из эксплуатации угольных ТЭЦ (Великобритания, США). Там, где уголь остаётся наиболее доступным и дешёвым источником энергии, угольная генерация просто переходит на более современную и экологически безопасную технологическую платформу [Зимаков, 2017; Мамонова, 2018; Хохлов, 2018; Угольная генерация.., 2019].

Часть стран считает, что дальнейшее использование угля для производства электроэнергии несовместимо с реализацией 
задачи резкого снижения выбросов парниковых газов². В 2017 г. на Международной конференции ООН по климату 27 государств (Канада, Великобритания, Франция, Италия и др.) объединились в альянс Powering Past Coal Alliance (Альянс поэтапного отказа от угольной генерации), членство в котором предусматривает прекращение использование угля в энергетике, но лишь 13 из этих государств имеют действующие угольные электростанции.

В США закрытию угольных станций способствовали резкое наращивание добычи газа, его удешевление и бум строительства газовых станций. Энергетика на основе ВИЭ оказывала значительно меньшее влияние. Но с приходом к власти Трампа оценка приоритетности использования энергоносителей изменилась, и в настоящее время происходит корректировка энергетической политики.

Страны Евросоюза, формально поддерживая общее стремление к экологически чистой энергетике, движутся в этом направлении каждая своим путем. Польша, энергетика которой является наиболее угольнозависимой среди всех стран Европы, приняла «Энергетическую политику Польши 2050», в которой намечено к 2030 г. вывести из эксплуатации 12 ГВт старых угольных мощностей. При этом планируется модернизировать 11,9 ГВт угольных ТЭЦ, фактически компенсируя это выбытие. Тем самым Польша не спешит отказываться от дешёвого и доступного сырья для производства электроэнергии и не предпринимает конкретных шагов, направленных на снижение доли угля в энергетике [Зимаков, 2017].

В Германии из-за принятых политических решений об отказе от использования атомной энергии замещение выбывающих мощностей АЭС стало тяжелым бременем. В энергобалансе этой страны на каменный и бурый уголь приходится суммарно около 40\%, примерно 29\% всей генерации дают возобновляемые источники, $13 \%$ - у АЭС и $12,4 \%$ - у газовых электростанций. При этом альтернативная энергетика оказалась, во-первых, недостаточно освоенной (доля в выработке по-прежнему низка), во-вторых, очень дорогой по сравнению с традиционной. Расходы на ее субсидирование, по данным Euracoal. Annual Report 2012 за период с 2000-2012 гг, превысили 100 млрд евро. Таким образом, дальнейший переход на ВИЭ плохо сочетался с политикой

${ }^{2}$ Угольная пятилетка // Интернет-портал Переток.ру, 14 Апреля 2016 URL: https://peretok.ru/articles/strategy/12661/ (дата обращения: 10.04.2019). Carbon Brief. URL: ttps://www.carbonbrief.org/analysis-bp-significantly-upgrades-global-outlook-wind-solar-again 
бюджетной экономии. Выход был найден в обращении к самому традиционному и дешевому энергоресурсу - углю. Угольная генерация была признана вполне подходящей переходной технологией на пути от атомной к альтернативной энергетике. В Германии уже строятся или проектируются 23 новые угольные ТЭЦ, по оценкам Greenpeace, их мощность превысит 24 ГВт. Это дает повод экспертам сомневаться, что стране удастся достичь запланированного 40\%-го снижения выбросов углекислого газа к 2025 г. [World., 2018; Угольная генерация..., 2019], и многие из них не видят альтернативы возврату к атомной энергетике.

Помимо Польши и Германии, стремление развивать угольную генерацию с целью уменьшить зависимость от импорта природного газа проявляли такие страны, как Турция, Сербия, Босния и Герцеговина. Таким образом, в Европе экономические ценности оказались сильнее политических программ и целей.

Разумным подходом отличается Китай. В планах страны закрытие многих сотен мелких, старых и малоэффективных установок и замена их более крупными и современными [ХоХлов, 2018, Угольная генерация..., 2019]. Около 20\% угольных станций в Китае уже сейчас относится к сверхэффективным (т.е. применяют ультра- и сверхкритические технологии HELE (high efficiency low emissions - высокая производительность, низкие выбросы). КНР вводит всё более жесткие требования к выбросам функционирующих угольных ТЭС - выбросы будут приведены к уровню газовых, самых экологичных на сегодняшний день электростанций, использующих невозобновляемые энергоресурсы. В 2019 г. эти нормы распространятся на Центральный Китай, а с 2020 г. станут обязательными для всей страны. Фактически китайский «уголь» становится чище и эффективнее европейского и американского, как в плане выбросов, так и КПД. Примечательно, что если судить по снижению коэффициента использования установленной мощности угольных электростанций, отмечаемому рядом исследователей, то принимаемые в 2020 г. нормы позволят не только улучшить экологическую ситуацию, но и срезать нарост избыточных, неэффективных мощностей ${ }^{3}$.

${ }^{3}$ Догорающая суперзвезда: уголь. Рамблер. 10 июня 2018 URL: https://news.rambler. ru/other/40070987/?utm_content=rnews\&utm_medium=read_more\&utm_source=copylink 
В целом, можно сделать вывод, что отсутствие единства подходов и условий в разных странах позволит угольным ТЭС удержать довольно высокую долю в производстве электроэнергии в среднесрочной перспективе, однако в на длительном горизонте можно ожидать сокращения доли угольной генерации [World., 2018; Зимаков, 2017 и др.]

По мнению Международного энергетического агентства (МЭА), угольная генерация перешла в фазу «драматического замедления», так как Китай, который все последние годы обеспечивал большую часть прироста, уже не нуждается в новых угольных ТЭС.

В базовых сценариях крупных мировых агентств (ИЭА, Блумберг, ВР, Ехxоn и др.) прогнозируется, что к 2040 г. доля угольной генерации в структуре мирового производства электроэнергии сократится до 23-25\% (хотя по объемам выработки останется на прежнем уровне). Более радикальных изменений глобальной топливной корзины эксперты не ожидают - мир попрежнему не готов снизить зависимость от ископаемых видов топлива.

По прогнозам МЭА, в предстоящие пять лет спрос на уголь будет расти лишь за счёт Индии и стран АСЕАН, в то время как в Европе, США и Китае его потребление будет сокращаться. Согласно данным Carbon Brief и CoalSwarm, по состоянию на 2017 г. ${ }^{4}$ действующие мощности угольной генерации составили 1996 ГВт, 210 ГВт находились в стадии строительства, 443 ГВт - на этапе планирования. По информации составителей, за 2000-2017 гг. было предложено построить 1681 ГВт угольных энергомощностей, но затем большинство проектов были отменены или отложены. Лишь 34\% (873 ГВт) были построены или переведены в состояние строительства. При этом за несколько лет в странах ЕС и США были закрыты 200 ГВт угольных ТЭС, еще 170 ГВт должны быть остановлены до 2030 г.

Отметим, что все государства, реализующие программы по выходу из угольной энергетики, сталкиваются с трудностями, связанными с необходимостью закрытия крупных эффективно

\footnotetext{
${ }^{4}$ Сервис Carbonbrief показывает все угольные ТЭС свыше 30 МВт каждая, работавших в период 2000-2017 гг., а также местоположение планируемых. Карта включает около 10000 закрытых, действующих и планируемых угольных установок общей мощностью 4567 ГВт. (URL: https://www.carbonbrief.org/mapped-worlds-coal-power-plants).
} 
работающих предприятий, многие из которых имеют регионообразующий характер [Новые прогнозы.., 2018; World.., 2018]. Плюс к тому после закрытия угольных станций у многих из них возникает потребность поддержки угледобывающих регионов.

\section{Специфика энергетики в России. Ниша угольной генерации}

В некотором смысле Россия возглавляет общемировой тренд. Постепенный «отказ от угля» в энергогенерации, к которому многие развитые страны только подступают, в нашей стране реализуется уже с 1970-х годов - в результате освоения газовых месторождений Западной Сибири начался масштабный перевод ТЭС (главным образом - в европейской части страны) с твердого топлива на газ. В результате в структуре выработки электроэнергии на тепловых электростанциях доля угля в России является одной из самых низких из экономически развитых стран - с 2000 г. по 2018 г. она снизилась с 27\% до 16\%. В структуре мощности доля угольной генерации за это же время сократилась с 29 до 22\% (рис. 1). Постепенное вытеснение угля из российской генерации продолжается. Так, за период с 2000 г. по 2017 г. в структуре мощности энергетики России произошел рост доли АЭС, при сокращении доли ТЭС.

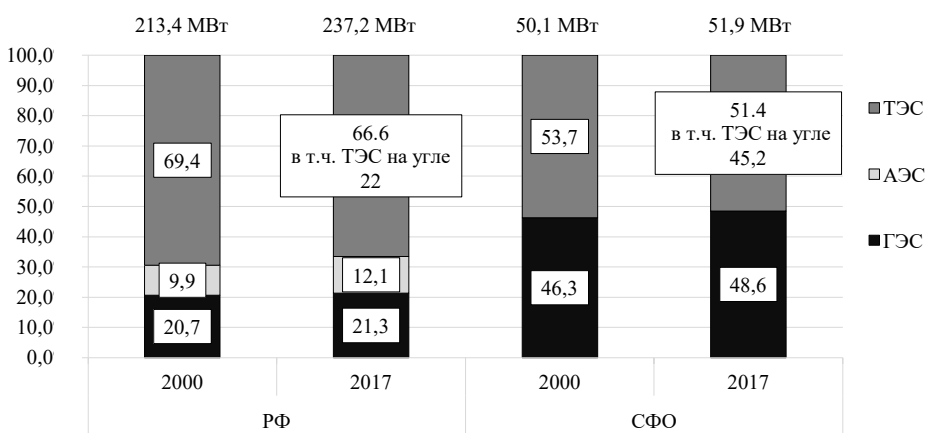

Puc. 1. Структура мощности по видам генерации России и Сибири в 2000 г., 2017 г.,\%

На данный момент из 256 российских ТЭЦ и ГРЭС на угле работают лишь около 110, играя важную роль в общем энергобалансе России и системообразующую - в региональных 
энергобалансах. Электростанции, использующие уголь, наряду с нетопливными источниками вносят существенный вклад в диверсификацию топливного баланса страны ${ }^{5}$. Основные мощности российских угольных станций сосредоточены в Сибири (45\% от российских, или 24,5 из 56 ГВт), высока доля угольной генерации также на Дальнем Востоке (42\%) и в Уральском ФО (21\%). В последние годы доля угольной генерации в структуре выработки составляет в РФ - 15-17\%, СФО - 49-58\% (рис. 1).

В рамках договоров на поставку новой мощности в 20082015 гг. (программа ДПМ-1) строились преимущественно газовые электростанции (80\%), тогда как угольная генерация приросла всего на 2 ГВт (или 9\% от общего объема новых мощностей). Этот перекос не позволил в рамках предыдущего инвестцикла не то что переломить, но даже остановить объективный процесс «старения» угольных электростанций. Несмотря на новые вводы на ряде угольных ТЭЦ (Барнаульской-2, Благовещенской, Абаканской, Красноярской-3) и КЭС (Троицкой, Черепетской, Березовской и Новочеркасской ГРЭС), ситуация в угольной энергетике постоянно ухудшается: в 2018 г. средний возраст оборудования достиг 38 лет. При этом газовые ТЭС в среднем «моложе» угольных на пять лет, но, что гораздо важнее - за счет запуска газотурбинных (ГТУ) и парогазовых установок (ПГУ) они стали заметно более эффективными.

В целом, реализация программы ДПМ-1 привела к ряду негативных для угольной генерации последствий: рост использования газа на ТЭС обернулся снижением цен на электроэнергию, что подкосило конкурентоспособность угольных станций и повлекло снижение их загрузки, а в итоге - увеличение себестоимости производства на угольных ТЭС.

Программа ДПМ-2, предложенная в июне 2018 г. Минэнерго, нацелена главным образом на модернизацию старых генерирующих мощностей. Приоритет - частичная замена основного оборудования (котлы, турбины) на аналогичное, капиталоемкость до $50 \%$ от нового строительства. При этом проекты комплексной замены блоков на улучшенные новые типы не рассматриваются -

\footnotetext{
${ }^{5}$ Веселов $Ф$. Развитие межтопливной конкуренции в российской электроэнергетике. Доклад на круглом столе «Газовая и угольная генерация России: реалии и перспективы» 50-го заседания форума «Нефтегазовый диалог» ИМЭМО РАН совместно с Российским газовым обществом. 26 мая 2015, URL: https://www.eriras.ru/data/633/rus
} 
нет инновационного заказа для поставщиков. В рамках программы предполагается возврат инвестиций на обновление ТЭС совокупной мощностью 41,3 ГВт до 2031 г. (из них мощности сверх 40 ГВт получают лишь незначительные финансовые ресурсы для продления срока эксплуатации).

В центре страны и на Урале (1-я ценовая зона) в первую волну программы попали 29 газовых станций, в Сибири (2-я зона) 16 угольных ТЭС. Предельный объем обновления во 2-й ценовой зоне - 7,8 ГВт (около 30\% от установленной мощности угольной генерации в СФО). Кроме того, 200 млрд руб. из общего объема инвестиций в 1,9 трлн руб. будут направлены на модернизацию в неценовых зонах.

За пределами 2031 г. решения по модернизации угольной энергетики пока не предложены. В стратегических документах развития отрасли, подготовленных до 2008 г. («Энергетической стратегии России на период до 2020 г.» и «Генеральной схеме размещения объектов электроэнергетики на период до 2020 г.») была дана целевая установка на опережающее развитие угольной генерации. Основным доводом для этого называлась необходимость повышения диверсификации «топливной корзины» отечественной энергетики для обеспечения необходимого уровня энергобезопасности. Но надежды на высокие темпы роста потребления электроэнергии, заложенные в названных документах, не оправдались: начиная с 2010 г. спрос стагнирует, а значит, отсутствует потребность в новых мощностях. К тому же экономический кризис 2009 г. повлек изменение инвестиционных программ энергокомпаний. В более поздних редакциях вышеназванных стратегических документов и принятой позднее «Долгосрочной программе развития угольной промышленности на период до 2030 г.» (2012 г.) вектор «опережающего развития угольной генерации» в соответствии с реальными экономическими процессами, происходящими в стране, был изменён на «незначительный темп роста». В каждом последующем прогнозном документе объёмы потребления угольного топлива в энергетике сокращались (рис. 2). Действующая Энергетическая стратегия России до 2035 г. предполагает, как минимум, сохранение доли угольной генерации на уровне $1 / 5$ от установленной мощности и при небольшом росте абсолютных значений. 
Вместе с тем в Минэнерго и многие отраслевые специалисты считают, что в Сибири и на Дальнем Востоке уголь «не имеет экономически адекватных альтернатив» [Прогноз развития..., 2016; Макаров, 2017]. Газ на этой обширной территории может рассматриваться в качестве альтернативы углю только в регионах, расположенных в зоне Единой газотранспортной системы, а развитие АЭС ограничено европейской частью РФ. В то же время масштабное развитие зеленой генерации сдерживается ее высокой себестоимостью.

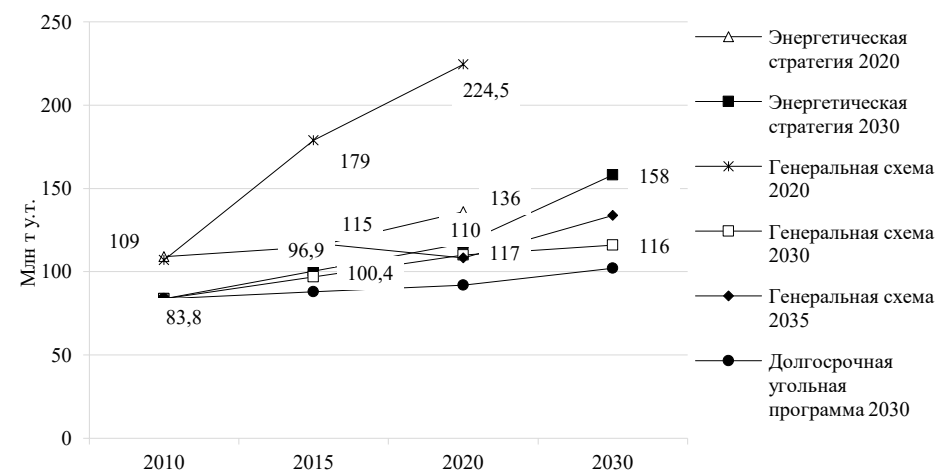

Puc. 2. Объемы потребления угля на ТЭС в РФ (ориентиры стратегических документов) ${ }^{6}$ в $2010-2030$ гг., млн т у.т.

\section{Технологическое развитие угольной генерации как ответ вызовам}

Для сохранения своей роли в обеспечении нового индустриального развития угольной генерации требуются новые технологии, которые позволят использовать преимущества угля и нивелировать его экологические недостатки. И в мире найдены успешные технологические решения [Угольная генерация, 2019; Technology Roadmap, 2012; Clean Coal Technologies, 2014; World.., 2050, 2014 и др.].

\footnotetext{
${ }^{6}$ Программа развития угольной промышленности до 2030 г. /утв. распоряжением Правительства РФ 21.06.2014 № 1099-р. Проект Энергетической стратегии России на период до 2035 года. M., 2016 г., URL: http://www.energystrategy.ru/ab_ins/source/ ES-2035_09_2015.pdf (дата обращения: 10/05/2019). Генеральная схема размещения объектов электроэнергетики до 2030 года. M., 2010, URL: http://www.e-apbe.ru/scheme (дата обращения: 10.05.2019). Генеральная схема размещения объектов электроэнергетики до 2035 года / утв. распоряжением Правительства РФ от 9 июня 2017 г. № 1209-р.
} 
«Угольный» сценарий может состоять в стимулировании угольной энергетики, «привязанном» к повышению ее эффективности и «чистоты» [Мельников, 2018]. В России, к примеру, речь может идти о развитии угольных ТЭЦ с закрытием угольных котельных, развитии отечественных технологий «чистого угля», серьезной модернизации отрасли - в том числе с использованием уже запускаемых механизмов на рынке тепловой (альтернативная котельная) и электрической энергии (ДПМ-2) и дополнительных источников. Для перевода на новейшие технологии нужны политическая воля и экономические стимулы. В целом, по мнению и энергетиков, и властей, и экспертов, есть понимание, что проблема будущего угольной генерации комплексна и неоднозначна, и простых быстрых решений тут быть не может [Некрасов, 2017, Новые прогнозы..., 2018; Макаров, 2017; Горбачева, 2016].

Еще в Прогнозе научно-технического развития ТЭК, утвержденном Минэнерго РФ в 2016 г., было сказано, что в краткои среднесрочной перспективе в угольной генерации требуются разработка и освоение производства новых паровых турбин, необходимых для замещения выводимых энергоблоков, а также нового теплофикационного блока мощностью 100-120 МВт «с повышенными технико-экономическими показателями» ${ }^{7}$. Отмечалась там и потребность в типовых проектах угольной ТЭЦ нового поколения, «учитывающей современные схемные и компоновочные решения с внедрением инновационных технологий, обеспечивающих возможность использования золошлаковых отходов в строительной индустрии». Емкость внутреннего рынка для угольных ПТУ ведомство оценивало в 10-20 ГВт, или 100-120 энергоблоков мощностью 100-330 МВт на период до 2035 г.

Модернизация ТЭС. Избыток устаревшего оборудования диктует необходимость масштабной модернизации действующих ТЭС. Должен быть приоритет повышения эффективности использования энергетических мощностей по отношению к увеличению мощности энергосистемы. Развитие энергетики во всех странах сопровождалось ростом числа часов использования мощности, что приводило не только к сокращению доли постоянных издержек в цене электроэнергии, но и к уменьшению удельного

\footnotetext{
${ }^{7}$ Прогноз научно-технического развития отраслей ТЕК на период до 2035 г. Москва. 2016. 110 c. URL: https://minenergo.gov.ru/system/download-pdf/6366/67618
} 
расхода топлива за счет работы оборудования в оптимальных режимах. Низкий уровень загрузки электростанций является «коррозийным» для экономики угольных ТЭС. В целом, они рассчитаны на эксплуатацию не менее $80 \%$ времени, так как имеют относительно высокие постоянные затраты [Некрасов, 2017]. Это также является основой сметы расходов на строительство нового угольного блока, в то время как меньшая загрузка повышает затраты на единицу электроэнергии.

В России действующие правила оптового рынка электроэнергии и мощности (ОРЭМ) также формируют сигналы о неэффективности и невостребованности угольной генерации, что вынуждает генерирующие компании выводить их из эксплуатации. Цены рынка конкурентного отбора мощности (КОМ) в ценовых зонах РФ отличаются практически вдвое - 119,6 тыс. руб. за МВт/ мес. в первой против 200,2 тыс. руб./мес. - во второй (на 2018 г.). И это при среднемесячных удельных постоянных затратах угольных блоков первой ценовой зоны в 200 тыс. руб./МВт. По оценке Ассоциации «Совет производителей энергии», себестоимость угольной генерации в первой ценовой зоне сегодня не покрывают ни цены рынка на сутки вперед, ни регулируемые договоры. В текущих рыночных условиях, при сохранении низких цен конкурентного отбора мощности и тарифов по регулируемым договорам, высокого водного налога, транспортных расходов, угольные станции первой ценовой зоны не конкурентоспособны ни на рынке электроэнергии, ни на рынке мощности ${ }^{8}$ [Попов, 2018].

Строительство новых крупных станций. В настоящее время предпосылок к интенсивному развитию угольной генерации в России нет. По мнению многих специалистов [Угольная генерация.., 2019; Григорьев, 2018; Макаров, 2017; и др.] и авторов статьи [Чурашев, Маркова, 2014; Маркова, Чурашев, 2017], существенного роста доли угольных ТЭС в топливном балансе страны ожидать не стоит. Как следствие, при таких экономических условиях доля угольной генерации в России в целом к 2030 г. в лучшем случае оценивается на уровне $25 \%$.

Один из немногих факторов, определяющих жизнеспособность угольной генерации в такой ситуации-относительно низкая

${ }^{8}$ Попов A. Есть ли будущее у угольной генерации в России? //Кислород-лайф. 2019. 14 января.URL:http://kislorod.life/question_answer/est_li_budushchee_u_ugolnoy_ generatsii_v_rossii/ (дата обращения: 10.04.2019). 
зависимость от стоимости топлива. Инвестиции в строительство новой угольной станции составляют $51 \%$ общих издержек генерации электроэнергии в процессе жизненного цикла станции, и только 13\% приходится на топливные затраты [Угольная генерация.., 2019]. У электростанций, работающих на газе, соотношение капитальных и текущих затрат иное: 30\% против 60\%, то есть они гораздо более чувствительны к стоимости топлива. В то же время, согласно постановлению правительства о параметрах договоров о предоставлении мощности (ДПМ, Постановление Правительства РФ от 13.04.2010 № 238), уровень капитальных затрат на строительство 1 кВт угольной мощности закреплен в 49-53 тыс. руб., газовой - в 29-42 тыс. руб. Эксплуатационные затраты угольных станций также выше (в постановлении о ДПМпримерно на 53\%).

При этом в регионах Сибири и Дальнего Востока угольная энергетика имеет больше шансов на развитие - в условиях относительной территориальной близости источников добычи и потребления угля. Но в перспективе до 2030 г. подобные проекты для удовлетворения внутренних потребностей здесь не просматриваются. Если же иметь в виду развитие угольной генерации с экспортной направленностью, оно возможно только в СФО и ДФО, но целесообразно лишь при интеграции энергетического пространства Северо-Восточной Азии. Планируемая уже десять лет Ерковецкая ТЭС в Амурской области мощностью 5-7 ГВт (беспрецедентный для России уровень, сопоставимый с мощностью всех тепловых электростанций ДФО) - это всего лишь 2\% от строящихся угольных станций в Китае и 6\% от величины их годового ввода.

Технологии «чистой» угольной энергетики. Технологии, позволяющие угольной энергетике приобрести имидж «чистой»-Clean coal technology (CCT) - носят общее название HELE (high efficiency low emissions - высокая производительность, низкие выбросы), и их можно разделить на несколько направлений [HELE Perspectives, 2018; Energy Technology.., 2014; Technology Roadmap, 2012]:

$\Delta$ технологии улавливания и хранения $\mathrm{CO}_{2}$ (CCS);

$\Delta$ повышение эффективности (пылеугольное сжигание (ультра- и сверхкритические параметры пара), газификация угля;

$\Delta$ очистка и удаление золы;

$\Delta$ совместное сжигание с биомассой;

$\Delta$ очистка дымовых газов, снижение выбросов. 
Ряд специалистов полагают, что в среднесрочной перспективе наиболее актуален переход на «ультра- и сверхкритические» технологии сжигания угля (то есть при предельно высоких температурах и давлении), КПД которых доходит до 46\%. Для сравнения: средний КПД угольной электростанции в мире составляет 33\%. Однако пока ни темпы, ни масштаб внедрения упомянутых технологий не соответствуют задачам инновационного развития энергетики. Более половины угольных электростанций, введенных в эксплуатацию с 2006 по 2010 гг. во всем мире, были спроектированы на основе традиционных технологий с использованием докритических параметров пара. Только начиная с 2012 г. ввод был за счет новых технологий. В настоящее время угольные ТЭС последнего поколения с принципиально новыми технологиями улавливания углекислого газа запущены в Китае (GreenGen в Тяньцзине) и США (Edwardsport в Индиане), ряд проектов находятся в завершающей стадии строительства в США (Kemper Country, Hydrogen Energy California, Summit Texas Clean Energy) и Японии (Osaka).

В мире мощность угольных ТЭС с ультрасверхкритическими параметрами пара составляет 266 ГВт (13\% от общей величины), лидеры в этой области - Япония (35\%), Южная Корея, Китай. В Азии более современные ТЭС, чем в Европе и Северной Америке, и многие из них оснащены технологией HELE [Хохлов, 2018; HELE Perspectives, 2018; Мельников, 2018].

В России же угольные ТЭС с ультрасверхкритическими параметрами пара отсутствуют полностью, доля ТЭС на сверхкритических параметрах - всего $2 \%$, а треть ТЭС работает на давлении 9 МПа, характерном для СССР 1950-х годов и Китая 1960-х [Clean Coal Technologies, 2014; Угольная генерация..., 2018]. Внедрение современных технологий сдерживают дешевый уголь и отсутствие отечественного оборудования.

В долгосрочной перспективе, по мнению технических специалистов, большим потенциалом обладает технология цүиркуляциионного кипящего слоя, которая при сниженных выбросах улучшает маневренные свойства станций. Хотя требования к выбросам в России остаются крайне мягкими на фоне того же Китая, угольным станциям в любом случае придется стать «чище». Реализация этой задачи упирается в недостаток очистного оборудования отечественного производства, не говоря уже о системах улавливания и хранения углерода (Carbon capture storage - CCS), 
которые пока для России выглядят совершенной фантастикой [Угольная генерация.., 2019].

Важным мировым трендом является совместное сжигание угольного топлива с биомассой. На сегодня практически половина из 10-12 млн т пеллет, производимых ежегодно в мире, используются на ТЭЦ для выработки электроэнергии. Особенно широко это практикуется в европейских странах, подписавших Киотский протокол (Бельгии, Нидерландах, Дании, Швеции и Великобритании). Так как пеллеты, в отличие от других видов биотоплива, обладают хорошими энергетическими характеристиками, а их гомогенность облегчает транспортировку и хранение, владельцы крупных ТЭЦ все охотнее заменяют ими часть угля. При их совместном сжигании сокращаются выбросы парниковых газов, уменьшаются эксплуатационные затраты.

В России есть пока лишь отдельные примеры эффективных решений повышения КПД угольных станций. Так, на НовоИркутской ТЭЦ каждую зиму растапливают уникальный котел с кольцевой топкой, КПД которого приближается к 93\%. Помимо экономической эффективности, агрегат отличают хорошие экологические характеристики: пониженная температура факела позволяет в полтора-два раза сократить выбросы оксидов азота.

В целом же, глобальные технологические тренды в развитии отрасли в России, по мнению ряда специалистов [Угольная генерация.., 2019; Григорьев, 2018, и др.] «преломляются» технологической отсталостью как самой отрасли (большая доля устаревших ТЭС), так и профильного машиностроения. А замедление роста или даже снижение энергопотребления усугубляет эту ситуацию.

По мнению экспертов Центра энергетики «Сколково» [Хохлов, 2018; Угольная генерация.., 2019], для российской экономики использование китайских технологий для глубокой модернизации угольной генерации, строительства новых крупных объектов, в том числе и для экспорта электроэнергии в Китай или Японию, - хорошая возможность обновить отрасль без дополнительных затрат на возрождение и развитие с нуля собственных компетенций (путь, по которому, наверное, можно идти в газовой энергетике).

В свою очередь специалисты Института проблем естественных монополий (ИПЕМ) [Григорьев, 2018] считают, что для модернизации угольной генерации чрезвычайно важна государственная 
поддержка энергетического машиностроения. Инструменты давно опробованы - на примере автопрома или тех же технологий ВИЭ, развитие которых стимулировалось не столько для решения экологических или климатических задач, сколько для локализации производств современного оборудования. Все это приобретает особую актуальность в преддверии принятия новой программы модернизации тепловой энергетики России.

\section{Особая роль угольной генерации в Сибири как источника теплоэнергии}

Большинство экспертных материалов, ярко демонстрирующих победное шествие ВИЭ в части производства электроэнергии, совершенно не учитывают климатические особенности ряда стран, для которых чрезвычайно важным остается производство теплоэнергии. К их числу, безусловно, относится и Россия.

В основе теплового обеспечения России находятся системы централизованного теплоснабжения (СЦТ), доля которых в суммарном производстве теплоэнергии превышает $80 \%$ (1300 млн Гкал в год). Ключевыми звеньями таких систем являются ТЭЦ. Однако сокращение потребления тепла от СЦТ почти вдвое за последние 30 лет, с одной стороны, и массовая котельнизация, с другой, привели к возникновению существенного избытка мощностей тепловой генерации: $30 \%$ от установленной мощности ТЭЦ и $15 \%$ - у котельных.

В Госдокладе о состоянии энергосбережения и повышении энергоэффективности в РФ (подготовлен Минэкономразвития РФ в 2017 г.) отмечено, что снижение удельных расходов топлива одно из позитивных последствий масштабной программы модернизации энергетики России, реализованной в рамках «первого» ДПМ. Однако все эти достижения - только в сегменте производства электричества. В сфере производства тепла «накопившиеся за последние 20 лет проблемы не позволяют заявить о существенном улучшении основных технико-экономических показателей». По данным доклада, только за 2000-2015 гг. общее число отопительных котельных в стране возросло с 68 до 74 тыс. (а к 2018 г. до 100 тыс.), а их доля в выработке теплоэнергии составляет около $50 \%$. Количество же мелких котельных с установленной тепловой мощностью до 3 Гкал/ч на конец 2015 г. составляло 57 тыс., притом что их средний коэффициент использования мощности не 
превышает 20\%. Очевидны также экологические минусы такой повальной «котельнизации» [Попов, 2018; Маркова, Чурашев, 2017].

В городах Сибири угольная энергетика, как правило, работает в режиме когенерации: выработки одновременно электричества и тепла. Но и здесь ТЭЦ, оставаясь ключевыми звеньями централизованных систем теплоснабжения, из-за всеобщей «котельнизации» 1990-х и начала 2000-х оказались сильно недогружены по теплу.

Разумеется, этот аспект требует учета при развитии различных направлений энергетики, включая альтернативные [Фахрутдинов, 2018]. К сожалению, массово принимаемые в последние годы схемы теплоснабжения муниципалитетов (это ключевой документ, определяющий долгосрочное развитие жизненно важной тепловой инфраструктуры), по мнению Минэнерго, изобилуют рядом системных недостатков: часто вместо имеющихся недозагруженных ТЭЦ загружаются менее эффективные и более затратные котельные, цены которых могут превышать тариф ТЭЦ в три раза и более; для обеспечения теплом новых потребителей вместо увеличения нагрузки на ТЭЦ за счет реконструкции и строительства тепловых сетей нередко принимается решение о строительстве новых источников теплоэнергии (как правило - с привлечением бюджетных субсидий), что влечет за собой дополнительный рост тарифов. Таким образом, существующая практика развития отрасли приводит к нарастанию неэффективности использования тепловых мощностей, увеличению финансовой нагрузки на потребителей, снижению доли выработки тепловой энергии в режиме когенерации, а также эффективности использования топливных ресурсов, и конечно, негативно отражается на финансово-экономических показателях ТЭЦ и централизованного теплоснабжения в целом.

В качестве второго ключевого недостатка принимаемых схем теплоснабжения эксперты часто называют отсутствие связи со схемами развития электроэнергетики.

Между тем в мире уже накоплен опыт решения подобных проблем в рамках развития распределенной генерации, которая сегодня превратилась в один из мировых трендов. Она стремительно развивается, имеет значительный потенциал рынка и впечатляющий набор технологических решений, трансфер которых, на наш взгляд, вполне возможен при достаточном уровне господдержки. Так, генеральная реконструкция районных 
котельных с переводом их в режим когенерации смогла бы удовлетворить потребности рассредоточенных потребителей в дополнительных объемах электрической и тепловой энергии. В мире насчитывается около 27 ГВт малых угольных ТЭС - до 30 МВт каждая. Мини-ТЭЦ на угле обладают в Сибири существенным потенциалом - как в зоне централизованного, так и децентрализованного теплоснабжения [Маркова, Чурашев, 2017]. В отличие от газовых мини-ТЭЦ, строительство которых возможно только вдоль трубопроводной магистрали, угольные (или биоугольные) могут покрыть практически не ограниченную территорию, используя местные ресурсы.

Отметим, что в Ф3-190 «О теплоснабжении» заявлен курс на приоритетное развитие именно теплофикационных источников, а децентрализация теплоснабжения путем переоборудования котельных в мини-ТЭЦ была прописана как один из путей развития в Прогнозе НТР отраслей ТЭК до 2035 года, выпущенном Минэнерго РФ в 2016 г.

Но у такого решения есть и противники, считающие, что оно целесообразно лишь в тех муниципалитетах, где не сложились системы централизованного теплоснабжения или «старые» ТЭЦ оказались полностью не эффективны (один из примеров - Рубцовск Алтайского края, который первым в стране ввел модель «альтернативной котельной»), а там, где сформированы системы центрального теплоснабжения с узловыми ТЭЦ, и особенно в крупных городах, заниматься переводом в режим мини-ТЭЦ многочисленных котельных не стоит.

Действительно, как показывает практика, в последние годы города все чаще идут по пути закрытия локальных котельных (полностью или выводя в резерв) с переводом их потребителей на снабжение от крупных ТЭЦ9 В результате замещение малых котельных способствует повышению тепловой нагрузки ТЭЦ и, как следствие, росту объемов теплофикации и улучшению экологических параметров отрасли. Экологический эффект от замещения котельных очевиден: ни одна из них не сможет сравниться с ТЭЦ по оснащенности, в том числе мощными электрофильтрами, улавливающими вредные вещества.

9 Лучше ТЭЦ, чем котельная. Кислород-лайф. 28 Ноября 2018. URL: http://kislorod. life/analitics/likbez_38_luchshe_tets_chem_kotelnaya/ 
Что касается перспектив развития существующей децентрализованной зоны энергоснабжения, повышение качества, надежности и эффективности последнего (особенно в арктических районах) возможно за счет замещения дизельных электростанций угольными ТЭЦ малой мощности. Согласно исследованиям ИСЭМ СО РАН, себестоимость производства электроэнергии на мини-ТЭЦ в среднем вдвое ниже по сравнению с дизельными станциями, а себестоимость производства тепловой энергии соответствует аналогичному показателю на котельных. В случае замещения дизельных электростанций мини-ТЭЦ необходимость в части мощностей котельных отпадет. С учетом того, что удельный расход топлива на выработку тепла на мини-ТЭЦ меньше аналогичного показателя на котельных, экономия последних при завозе угля может составить 15-20\%, при этом полностью будет исключен завоз дизельного топлива. Все это позволит снизить объемы дотаций на энергоснабжение потребителей более чем в два раза.

Например, в Якутии сооружение мини-ТЭЦ на угле возможно в населенных пунктах, расположенных в относительной близости к потребителям либо речным транспортным артериям. Согласно региональной стратегии, строительство мини-ТЭЦ на замену котельных предполагается в десятке с лишним населенных пунктов (пос. Депутатский и пос. Зырянка, г. Среднеколымск, пос. Черский, пос. Нижнеянск и Чокурдах, пос. Батагай и Белая Гора, с. Хонуу).

Полигенерация. Основой энергетики будущего на базе использования твердых топлив следует считать энерготехнологические предприятия с комплексной переработкой топлива и получением широкой гаммы продуктов с высокими товарными свойствами с большой добавленной стоимостью. В мире из угля получают более пятисот продуктов: бензин, пластмассы, моторные масла, смазочные материалы, химические препараты и др. В главном угледобывающем регионе нашей страны - Кемеровской области технологии глубокой переработки угля нашли свое отражение в программе развития инновационного кластера «Комплексная переработка угля и техногенных отходов», предполагающей строительство нескольких энерготехнологических комплексов. Аналогичные проекты анонсированы властями Якутии, Тывы, Красноярского края. В Республике Хакасия под кураторством «Коулстар» разработан проект создания и развития Бейского 
угольного кластера до 2030 г., направленного на глубокую переработку каменного угля (в частности, планируется строительство центральной обогатительной фабрики рядового угля и заводов по производству взрывчатых веществ, жидкого топлива, химической продукции). Однако для того, чтобы эти проекты из декларационной стадии перешли в практическую плоскость, необходимо непосредственное участие в инвестиционных программах государства. Венчурное финансирование подобных проектов пока слабо развито.

\section{Экологические проблемы угольной генерации и возможности технологий}

Ограничение по выбросам. Перспектива введения углеродного налога в целях регулирования выбросов парникового газа сегодня считается одним из ключевых рисков для угольной генерации. Вообще ужесточение экологических норм год от года увеличивает себестоимость угольной генерации во многих странах от Европы до Индии и Индонезии и ставит ее в невыгодное положение по сравнению с газовой энергетикой. Газовые энергоблоки «чище» по выбросам, им не нужно иметь специальные площадки для золоотвалов. Владельцы же угольных станций должны постоянно совершенствовать свои очистные технологии, чтобы соответствовать растущим экологическим стандартам, и это порождает для многих из них серьезные экономические проблемы. Так, по мнению Financial Thinktank Carbon Tracker, к 2030 г. почти все угольные ТЭС в Европе станут убыточными ${ }^{10}$.

В Китае за 16 лет требования в среднем ужесточились в 5,5 раза по оксидам азота, в 13 раз по оксидам серы и в 70 раз по золе; диапазон допустимых значений концентрации сократился в 3-6 раз (по оксидам) и в 300 раз по золе. Китайские стандарты экологичности угольных ТЭС превзошли уровни, достигнутые в США и Евросоюзе, в 1,5-2 и более раз [HELE Perspectives, 2018; Хохлов, 2018].

В России в апреле 2018 г. Минприроды утвердило перечень из 300 предприятий, оказывающих наиболее неблагоприятное воздействие на окружающую среду - примерно десятую часть

\footnotetext{
${ }^{10}$ Мировой рынок угольной генерации. Электрические сети в Системе. URL: https:/electricalnet.ru/blog/obzor-mirovoi-rynok-ugolnoi-generatsii (дата обращения 11.05.2019)
} 
перечня занимают ТЭС (в том числе угольные - 15 ед.) Теперь каждая из них, начиная с 2019 г., должна будет получить для дальнейшего функционирования комплексное экологическое разрешение при условии реализации программы модернизации. В сентябре 2018 г. Минпромторг предложил проект постановления правительства, утверждающего новые, более жесткие требования к автоматическим средствам измерения и учета показателей выбросов загрязняющих веществ, фиксации и передачи информации для объектов из реестра.

Отдельным направлением может стать использование отходов углеобогащения и золошлаковых отходов (ЗШО). Современные системы золошлакоудаления позволяют значительно сокращать земельные и водные ресурсы, необходимые для эксплуатации угольных энергообъектов.

Ежегодно объем выработки ЗШО составляет свыше 22 млн т, и по данным экспертов, сегодня на российских станциях накоплено свыше 1 млрд т золы, а её переработка (например, на нужды строительства) пока развита не на полную мощность (рис. 3). Так, всего 3,5\% (так называемая зола уноса) улавливается воздушными или электрофильтрами (если они есть) и накапливается в бункерах, являясь готовым мелкодисперсным материалом, вполне пригодным для строительства. Подавляющая часть отходов (82-88\%) отправляется на золоотвалы, чей ресурс практически исчерпан (свыше 28 тыс. га), при этом затраты на строительство новых золоотвалов сравнимы со строительством новых станций. В развитых странах утилизируют 70-95\% от выхода ЗШО, а в Нидерландах и Дании $-100 \%$.

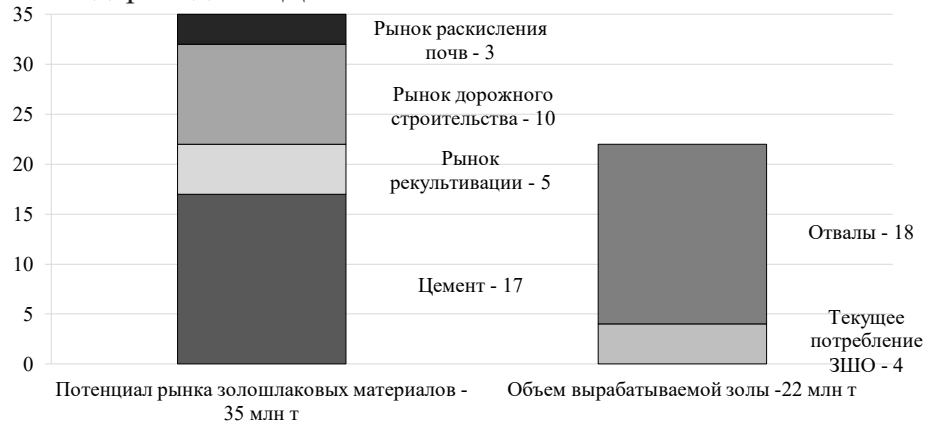

Источник: Минэнерго, ОАО ВТИ.

Puc. 3. Потенциал рынка золошлаковых отходов, млн т 
Всего 3-4 млн т золы, не более $10-15 \%$ от общего количества ежегодно образующихся отходов, в России используются для дальнейшей переработки в стройиндустрии, дорожном строительстве и других отраслях промышленности.

Основными причинами низкого уровня использования отходов тепловых станций эксперты Института проблем естественных монополий [Григорьев, 2017] считают отсутствие целенаправленной государственной политики по использованию ЗШО в плане организации или предоставления субсидий. Жесткие нормативы вредных выбросов в угольной промышленности и энергетике могли бы стимулировать более активную деятельность региональных властей и бизнеса по их сокращению, но для этого необходима политическая воля.

Компонентное содержание твердых и газообразных отходов угольной энергетики, большие масштабы их выхода позволяют рассматривать их как технологическое сырье для производства промышленной продукции. Так, зола некоторых угольных электростанций по содержанию окиси алюминия сопоставима с такими видами сырья, как нефелины, алуниты и др., и на базе этого сырья вполне возможна организация промышленного производства глинозема ${ }^{11}$.

Сегодня такой способ получения алюминия из золы активно используют в Китае, в 2012 г. был запущен масштабный проект в Тогто (Tuoketuo) [Yao Zhitong et al., 2014]. Согласно проектной документации, на первом этапе завод должен ежегодно производить 240 тыс. т оксида алюминия и 200 тыс т силиката кальция, а в последующем - вдвое больше. ЗШО также могут быть источником получения более дешевого урана.

Кроме того, для облегчения дальнейшего использования отходов угольной генерации в ИПЕМ предложили отказаться от устаревшего способа удаления золы (гидроудаление) в пользу альтернативных (сухое, полусухое и проч.) с созданием продуктов стабильного качества.

\section{Способы поддержки угольных станций}

Субсидирование развития возобновляемой энергетики существенно ухудшило позиции угольной генерации. Последняя,

\footnotetext{
${ }^{11}$ Проектная проработка строительства цементно-глиноземного завода на базе золы подмосковных углей. М.: Малое предприятие «Служба 11», 1991 г.
} 
по мнению основателя Bloomberg New Energy Finance Майкла Либрейха, сталкивается с двумя «переломными моментами». Первый - когда новая возобновляемая энергия становится дешевле новых угольных ТЭС, что уже произошло в нескольких регионах. Второй - когда новые возобновляемые источники энергии дешевле действующих угольных электростанций ${ }^{12}$.

Опыт экономического регулирования показал, что субсидирование развития возобновляемой энергетики дает толчок к повышению ее конкурентоспособность и ухудшает позиции традиционной энергетики. В ряде стран Юго-Восточной Азии в условиях реальной конкуренции угольная генерация начала проигрывать ВИЭ. В 2018 г. Китай, Вьетнам и Таиланд полностью отменили доплату производителям за солнечную генерацию, Филиппины и Индонезия существенно ее сократили. То есть в этих странах энергетика-ВИЭ по цене уже почти сравнялась с традиционной. Тем не менее, когда сторонники ВИЭ ссылаются на сокращение ее себестоимости, они часто не учитывают полную цепочку стоимости на всех этапах.

При необходимости и желании сохранить угольные станции государство может ввести для них специальные виды поддержки, например, в виде доплаты за мощность или субсидий для малых ТЭЦ, аналогичных тем, которые действуют в отношении ВИЭ.

Среди мер поддержки неконкурентоспособных электростанций, которые по тем или иным причинам должны быть сохранены (в качестве резерва, во избежание монотопливости, из-за социальной значимости предприятия, отсутствия реальной альтернативы в регионе и т.д.), в РФ рассматриваются:

- присвоение статуса вынужденных (такой статус был присвоен в 2015 г. шести угольным станциям, которые не смогли пройти конкурентный отбор мощности на общих условиях);

- пересмотр параметров ДПМ (в сторону увеличения доли угольных станций);

- сохранение текущих угольных мощностей в СФО и ДФО;

- сохранение диверсифицированного баланса (без существенного перекоса в сторону газовых станций или других видов генерации).

\footnotetext{
${ }^{12}$ Мировой рынок угольной генерации. Электрические сети в Системе. URL: https://electricalnet.ru/blog/obzor-mirovoi-rynok-ugolnoi-generatsii (дата обращения: 11.05.2019).
} 
Один из ярких примеров «административного» поддержания на плаву убыточной угольной станции - Новочеркасская ГРЭС. Предприятие является самым крупным потребителем (65-70\%) угля, добываемого в Ростовской области, что придает вес аргументам по ее сохранению в регионе. Весной 2019 г. Минэнерго предложило устанавливать цену на мощность для НчГРЭС из экономически обоснованных затрат (рассчитывает ФАС) в виде надбавки на оптовом рынке. Эта практика может распространиться и на другие угольные станции в первой ценовой зоне.

В Калининградской области строится Приморская ТЭС мощностью 195 МВт, в одну из задач которой входит диверсификация топливного баланса региональной энергосистемы. На станции предполагается использование кузнецкого угля, пуск запланирован на 2020 г.

После завершения отбора проектов для программы ДПМ-2 российское правительство, как и было обещано, вернулось к обсуждению перспектив продления программы поддержки «зелёной» генерации. Тем более что в результате окончания программы ДПМ-1 должны быть «высвобождены» средства потребителей. Министерство экономического развития, ранее разделявшее коллективное мнение регуляторов сектора о необходимости сокращения поддержки ВИЭ за счёт потребителей оптового рынка, вдруг резко сменило риторику и фактически перешло на позиции ВИЭ-генераторов. Министерство предложило в 2025-2035 гг. построить по прежней схеме (ДПМ-1) ещё 10 ГВт «зелёных» мощностей, оценив дополнительные расходы потребителей в 0,9 трлн руб. до 2050 г. Еще в 2018 г. возможная нагрузка на потребителей при продлении мер поддержки зелёной энергетики оценивалась «всего лишь» в 400 млрд руб. до 2035 г. ${ }^{13}$

Кроме того, министерство предлагает внести ряд изменений в условия и порядок отбора проектов. В частности, ранжировать их не по капзатратам, а по одноставочной цене (LCOE) $)^{14}$, ежегодно снижать «потолок» тарифа, обязать инвесторов поставлять часть

\footnotetext{
${ }^{13}$ Отметим, что в борьбу за «высвобождающиеся средства» включились также гидрогенераторы, которые предложили при продлении программы отменить ограничения по мощности сейчас в программу попадают только «малые ГЭС» до 25 МВт) и забронировать под них не менее 3 ГВт.

${ }^{14} \mathrm{LCOE}-$ средняя расчетная себестоимость производства электроэнергии на протяжении всего жизненного цикла электростанции.
} 
оборудования на экспорт, введя понижающие коэффициенты к плате за мощность при невыполнении нормы и т.д. Разумеется, все эти меры ставят угольную генерации в еще более затруднительное положение.

\section{Заключение}

Несмотря на все аргументы экологов, безальтернативное сокращение угольных станций вряд ли можно признать целесообразным как в России, так и во всем мире. Более того, при условии внедрения новейших технологий угольная генерация вполне может быть экологически безопасной. Но для этого нужны господдержка и экономические стимулы. В этих условиях «крестовый поход против угля» теряет смысл. Особенно это отвечает интересам России, обладающей богатейшими запасами этого вида топлива.

В целом, профессиональные участники рынка, власти и независимые эксперты сходятся во мнении, что проблема будущего угольной генерации комплексна и неоднозначна, и простых быстрых решений пока никому найти не удалось.

На мировом рынке, по мнению большинства экспертов, угольные ТЭС еще достаточно долго будут сохранять свою значимость в выработке электроэнергии, хотя ожидается существенное замедление динамики ввода новых мощностей. При этом будет усиливаться региональная дифференциация.

В России ожидается небольшой рост объемов выработки угольной генерации на горизонте до 2040 г., в том числе за счет модернизации имеющихся мощностей и новых вводов, однако ее доля в энергобалансе продолжит снижаться, предположительно до уровня 12-13\%. В первую очередь - благодаря более быстрому росту мощностей других видов генерации.

\section{Литература}

Веселов Ф.В., Ерохина И.В., Макарова А.С., Хоршев А.А. Комплексная оценка эффективных масштабов обновления тепловых электростанций при обосновании рациональной структуры генерирующих мощностей на перспективу до 2035 года // Теплоэнергетика. 2017. № 3. С. 5-14.

Горбачева Н.В. Угольная генерация в условиях нового индустриального развития // Мировая экономика и международные отношения. 2016. Т. 60. № 6.C. 42-51. DOI: 10.20542/0131-2227-2016-60-6-42-51

Григорьев А. Социальные и экономические аспекты функционирования угольной генерации в регионах России.М.: ИПЕМ, 2018. 64 с. 
Зимаков А.В. Есть ли будущее для угольных ТЭС в Европе? //Вестник МГИМО-Университета. 2017. 5(56). C. 130-150 DOI 10.24833/2071-81602017-5-56-130-150

Макаров А.А., Митрова Т.А., Веселов Ф.В., Галкина А.А., Кулагин $B$. A. Перспективы электроэнергетики в условиях трансформации мировых энергетических рынков //Теплоэнергетика. 2017. № 10. С. 5-16

Мамонова Е. Будущее угольных ТЭС становится неопределенным// Российская газета. 2018. 10 февраля. URL: https://rg.ru/2018/10/02/budushchee-ugolnyhtes-stanovitsia-neopredelennym.html (дата обращения: 10.04.2019).

Маркова В.М., Чурашев В.Н. Возможности повышения эффективности и оптимизации структуры энергетики: роли "большой" и "малой" генерации // Мир экономики и управления. 2017. Т. 17. № 3. С. 62-84.

Мельников Ю. Падение гигантов. Уйдут ли в прошлое угольные электростанции// Forbes.ru. 12.12.2018. URL: http://www.forbes.ru/biznes/370285-padeniegigantov-uydut-li-v-prosh-loe-ugolnye-elektrostancii

Некрасов С.А. О приоритетах развития системы энергоснабжения Российской Федерации. ИНП РАН. Энергетический семинар № 178: 2017. 25 апреля. URL: https://ecfor.ru/publication/energeticheskij-seminar-178-o-prioritetah-razvitiyasistemy-energosnabzheniya-rossijskoj-federatsii/ (дата обращения: 10.04.2019).

Новые прогнозы мировой энергетики и место России в ней //Энергетический бюллетень. 2018. № 54, ноябрь. М.: Аналитический центр при правительстве РФ. 24 с.

Прогноз развития энергетики мира и России на период до 2040 г. / Под ред. А.А. Макарова, Л.М. Григорьева, Т.А. Митровой; ИНЭИ РАН-АЦ при Правительстве РФ. М., 2016. 196 с. ISBN978-5-91438-023-3

Угольная генерация: возможности и вызовы. М.: Центр энергетики Московской школы управления СКОЛКОВО, 2019. 84 с.

Фахрутдинов Р. Как энергобезопасность РФ зависит от угольной генерации // Газета.PУ. 10.12.2018. URL: https://www.gazeta.ru/business/2018/12/10/12089143. shtml (дата обращения: 10.04.2019).

Хохлов А. Очищение угля: чему Россия может поучиться у Китая // РБК. 2018. Декабрь. URL: www.rbc.ru/opinions/business/ 21/12/2018/5c1b7e439a7947 f76c69db2b (дата обращения: 10.04.2019).

Чурашев В.Н., Маркова В.М. Инновационный диалог энергетики и угольной промышленности // ЭКО. 2014. № 1. С. 26-40.

Annual Energy Outlook 2014 with projections to 2040. US Energy Information Administration URL: http://www.eia.gov/forecasts/aeo/pdf/0383 (accessed 11.05.2019)

BP Energy Outlook 2018. British Petroleum-BP, 2018, 108 p. URL: https://www. bp.com/en/global/corporate/energy-economics/statistical-review-of-world-energy.html

Clean Coal Technologies, Update 2014 - Global Market Size, Trends, Regulations and Key Analysis. IEA, 2014

Energy Technology Perspectives 2014. Harnessing Electricity's Potential. Paris, OECD/IEA, 2014. 372 p.

HELE Perspectives for Selected Asian Countries / IEA Clean Coal Centre, June 2018.

International Energy Outlook 2017. Energy Information Agency - EIA USA, Report Number: DOE/EIA-0484(2017), 2017, 76 p. 
Technology Roadmap. High-Efficiency, Low-Emissions Coal-Fired Power Generation. Paris, OECD/IEA, 2012. Available at: https://www.iea.org/publications/ freepublications/publication/TechnologyRoadmapHighEffi ciencyLowEmissionsCo alFiredPowerGeneration_WEB_Updated_March2013.pdf (accessed 11.05.2019).

World Energy Outlook- 2018(summary). International Energy Agency. Paris, 2018, 84 p. URL: https://www.iea.org/weo (accessed 11.05.2019).

World Energy Outlook-2017. International Energy Agency, Paris, 2017, 321 p. URL: https://www.iea.org/weo (accessed 11.05.2019)

World Energy Technology Outlook-2050. OECD Publishing, 2014, 226 p.

Yao Zhitong, Xia M.S., Sarker Prabir, Chen T. A review of the alumina recovery from coal fly ash, with a focus in China. Fuel. 2014. 120. 74-85. 10.1016/j. fuel.2013.12.003. www.researchgate.net/publication/259505206_A_review_of_the alumina_recovery_from_coal_fly_ash_with_a_focus_in_China (accessed 11.05.2019).

Статья поступила 15.08.2019.

Для цитирования: Чурашев В.Н., Маркова В.М. Остаться нельзя уйти: к вопросу о развитии угольной генерации в России// ЭКО. 2019. № 11. С. 63-93. DOI: 10.30680/ECO0131-7652-2019-11-63-93.

\section{Summary}

Churashev, V.N., Cand. Sci. (Econ.), Institute of Economics and Industrial Engineering, $S B$ RAS

Markova, V.M., Cand. Sci. (Econ.), Institute of Economics and Industrial Engineering, SB RAS, Novosibirsk State University, Novosibirsk

Stay or Leave: on Coal Generation Prospects in Russia

Abstract. The paper reviews the prospects of global and Russian coal generation in terms of its share in the power energy structure in the context of current economic, ecological and technological challenges. The challenges include climate change and transition to low carbon energy industry that lead to strict ecological requirements for power station emissions, growing number of renewable energy sources implemented with government support programs and multiple cost reduction, growing competition with (cheaper) gas. It is demonstrated that technological development plays a decisive role in survival of coal power station in the world as well as in Russia. There are a number of ways to preserve coal power generation such as modernization of heat power stations, building of new ones that utilize clean coal technologies (CCT and HELE), replacement of boilers with mini-heating stations, construction of energytechnological complexes. We conclude that Siberia has no viable alternatives to the coal energy. In view of lack of higher mid-term demand for electrical energy, new large coal stations are not likely to appear unless some generated energy is transmitted to South-East Asia.

Keywords: coal generation; Siberia; ecological and economic efficiency; power capacity; clean coal technologies 


\section{References}

Annual Energy Outlook 2014 with projections to 2040. US Energy Information Administration Available at: http://www.eia.gov/forecasts/aeo/pdf/0383 (accessed 11.05.2019).

BP Energy Outlook 2018. British Petroleum-BP, 108 p. Available at: https://www. bp.com/en/global/corporate/energy-economics/statistical-review-of-world-energy.html

Coal generation: possibilities and challenges. (2019). Moscow. SKOLKOVO Energy Centre, 84 p. (In Russ.).

Churashev, V. N., Markova, V. M. (2014). Innovation Dialogue of Energy and Coal industry. ECO. No. 1. Pp. 26-40. (In Russ.).

Clean Coal Technologies, Update 2014-Global Market Size, Trends, Regulations and Key Analysis. IEA, 2014.

Energy Technology Perspectives 2014. Harnessing Electricity's Potential. (2014). Paris, OECD/IEA. 372 p.

Forecast of world energy development and Russia for the period up to 2040. (2016). Moscow, ERI RAS - Analytical center for the Government of Russian Federation, 196 p. (In Russ.).

Fahrutdinov, R. (2018). How the energy security of the Russian Federation depends on coal generation. Gazeta.Ru. 10. 12. Available at: https://www.gazeta.ru/ business/2018/12/10/12089143.shtml (accessed 10.04.2019) (In Russ.).

Gorbacheva, N. V. (2016). Coal-Fired Power in the New Industrial Development. Mirovaya ekonomika i mezhdunarodnye otnosheniya, Vol. 60. No. 6. Pp. 42-51. DOI: 10.20542/0131-2227-2016-60-6-42-51 (In Russ.).

Grigoriev, A. (2018). Social and Economic Aspects of Coal Generation Functioning in the Regions of Russi. Moscow. IPEM. 64 p. (In Russ.).

Hohlov, A. (2018). Coal purification: what Russia can learn from China. RBC. Dec. Available at: www.rbc.ru/opinions/business/ 21/12/2018/5c1b7e439a7947f76c 69db2b (accessed 10.04.2019) (In Russ.).

HELE Perspectives for Selected Asian Countries / IEA Clean Coal Centre, June 2018.

International energy outlook 2017. Energy Information Agency - EIA USA, Report Number: DOE/EIA-0484(2017), 2017, 76 p.

Makarov, A. A., Mitrova, T. A., Veselov, F. V., Galkina, A. A., Kulagin, V. A. (2017).Perspectives of the Electric Power Industry Amid the Transforming Global Power Generation Markets. Teploenergetika Thermal Engineering. No. 10. Pp.5-16. (In Russ.).

Mamonova, E. (2018). The future of coal-fired tpp becomes uncertain. Rossiyskay gazeta, 10 feb, Available at: https://rg.ru/2018/10/02/budushchee-ugolnyh-tesstanovitsia-neopredelennym.html (accessed 10.04.2019).

Markova, V. M., Churashev, V. N. (2017). Possibilities of Increase in Efficiency and Structure Optimization of Power Industry: «Big» and «Small» Generation Roles. World of Economics and Management. Vol. 17. No. 3. Pp. 62-84. doi:10.25205/25420429-2017-17-3-62-84 (In Russ.).

Melnikov, Yu. The fall of giants. Whether coal-fired power plants will go into the past. Forbes.ru, 12.12.2018.Available at: http://www.forbes.ru/biznes/370285padenie-gigantov-uydut-li-v-prosh-loe-ugolnye-elektrostancii (accessed 10.04.2019) (In Russ.). 
Nekrasov, S.A. (2017). On Priorities for the Development of the Energy Supply System of the Russian Federation. Moscow, IEF RAS, Seminar № 178. 25 apr. https://ecfor.ru/publication/energeticheskij-seminar-178-o-prioritetah-razvitiyasistemy-energosnabzheniya-rossijskoj-federatsii/ (accessed 10.04.2019) (In Russ.).

New forecasts of world energy and Russia's place in it. (2018). Energy bulletin. No. 54, nov. Moscow: Analytical center for the Government of Russian Federation, 24 p. (In Russ.).

Technology Roadmap. High-Efficiency, Low-Emissions Coal-Fired Power Generation. (2012). Paris, OECD/IEA,.Available at: https://www.iea.org/publications/ freepublications/publication/TechnologyRoadmapHighEffi ciencyLowEmissionsCo alFiredPowerGeneration_WEB_Updated_March2013.pdf (accessed 11.05.2019).

Veselov, F. V., Erokhina, I.V., Makarova, A. S., Khorshev, A. A. (2017). Comprehensive Assessment of the Effective Scope of Modernization of Thermal Power Plants to Substantiate the Rational Structure of the Generating Capacities for the Future until 2035. Teploenergetika.Thermal Engineering. No. 3. Pp. 5-14 (In Russ.).

World Energy Outlook- 2018(summary). International Energy Agency. Paris, 2018, 84 p. https://www.iea.org/weo (accessed 11.05.2019).

World Energy Outlook-2017. (2017). International Energy Agency, Paris, 321 p. Available at: https://www.iea.org/weo (accessed 11.05.2019).

World Energy Technology Outlook-2050. (2014). OECD Publishing, 226 p.

Yao Zhitong, Xia M. S., Sarker Prabir, Chen T. (2014). A review of the alumina recovery from coal fly ash, with a focus in China. Fuel. 120. 74-85. 10.1016/j. fuel.2013.12.003. www.researchgate.net/publication/259505206_A_review_of_ the_alumina_recovery_from_coal_fly_ash_with_a_focus_in_China (accessed 11.05.2019).

Zimakov, A.V. (2017). Is there any future for coal power plants in europe? MGIMO Review of International Relations. Vol. 5(56). Pp.130-150. https://doi. org/10.24833/2071-8160-2017-5-56-130-150 (In Russ.).

For citation: Churashev, V.N., Markova, V.M. (2019). Stay or Leave: on Coal Generation Prospects in Russia. ECO. No. 11. Pp. 63-93. (In Russ.). DOI: 10.30680/ ECO0131-7652-2019-11-63-93. 